Coppen, A., Noguera, R., Bayley, J., Burns, B. H., Swani, M. S., Hare, E. H., Gardner, R. \& Maggs, R. (1971) Prophylactic lithium in affective disorders (controlled trial). The Lancet, ii, 275-9.

\section{LIVER CROSS-SENSITIVITY TO ANTIPSYCHOTIC DRUGS}

DeAR SIR,

Two points on management arise from this nearly fatal case.

A 26-year-old man admitted with acute schizophrenia sometimes accepted chlorpromazine but mostly he refused. Control of the psychosis was urgent because he would disappear into the freezing night in minimal clothing impelled by 'supernatural influence'. Over the next two weeks he accepted three injections of modecate which settled the psychosis.

Seventeen days after his first dose of phenothiazine, jaundice was noticed. For the next four months he was physically very ill. Serum bilirubin peaked at 252 (normal 0 17 umol/i), alkaline phosphatase reached 294 (normal 0-50 IU/L), GPT reached 240 (normal 0-40 IU/L), yGT reached 1675 (normal 0-50 IU/L).

A second psychotic episode settled in hospital without medication. The third episode in the same year was very severe and did not settle after compulsory admission. A literature search and drug company enquiry indicated that no antipsychotic drug is without risk to liver. Nothing was gleaned about relative risks of cross-sensitivity.

Arbitrarily it was decided to try in succession the best known drug derivative of each class of antipsychotic other than phenothiazine i.e. haloperidol, flupenthixol, pimozide. The shorter acting preparations would be given for at least two weeks before risking transfer to a long-acting depot preparation.
With regular liver funtion tests oral haloperidol was given for fourteen days when a sharp rise in SGPT and $\gamma \mathrm{GT}$ occurred. Oral flupenthixol was then given for three weeks when it was considered safe to establish him on the longacting depot prearation, Depixol, on which he has now been quite well for five months.

Point one In patients found to be sensitive to one antipsychotic drug, at least two weeks on short-acting preparations of the alternative drug is required before transferring to its long-acting depot preparation. The risks of inadequate control of a non-compliant psychotic patient have to be very great indeed to justify earlier depot injections which might damage the liver for many months.

Point two A register of alternative drugs tried in patients who have developed such liver reactions might eventually permit choices to be made which are better than arbitrary.

Bootham Park Hospital,

Peter Kennedy

York

\section{A CORRECTION: ALZHEIMER'S CLASSIC PAPER}

DEAR Sir,

Contrary to Dr Robin Jacoby's view (Reading About the Psychiatry of Old Age, May 1983) a full Englsh translation of Alzheimer's paper 'On a Peculiar Disease of the Cerebral Cortex' (1907) exists. It is by R. H. Wilkins and I. A. Brody (1969) Archives of Neurology, 21, 109-10.

St Bartholomews Hospital,

B. MAHENDRA 